\title{
Assessing patient safety in Canadian ambulatory surgery facilities: A national survey
}

\author{
Jamil Ahmad MD FRCSC ${ }^{1}$, Olivia A Ho MD², Wayne W Carman MD FRCSC ${ }^{3}$, Achilles Thoma MD MSc FRCSC FACS ${ }^{4}$, \\ Donald H Lalonde MD FRCSC ${ }^{5}$, Frank Lista MD FRCSC ${ }^{1}$
}

\begin{abstract}
J Ahmad, OA Ho, WW Carman, A Thoma, DH Lalonde, F Lista. Assessing patient safety in Canadian ambulatory surgery facilities: A national survey. Plast Surg 2014;22(1):34-38.
\end{abstract}

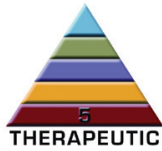

BACKGROUND: There has been increased interest regarding patient safety and standards of care in Canadian ambulatory surgery facilities where surgical procedures are performed. The Canadian Association for Accreditation of Ambulatory Surgical Facilities (CAAASF) is a national organization formed to establish and maintain standards to ensure that surgical procedures conducted outside of public hospitals are performed safely.

OBJECTIVE: To determine how many procedures are performed annually at CAAASF member sites, and to examine complication rates and several key patient safety practices.

METHODS: All 69 facilities accredited by the CAAASF were surveyed. The survey focused on procedural data, complication rates and patient safety interventions.

RESULTS: In 2010, 40,240 estimated procedures were performed. A total of $263(0.007 \%)$ complications were reported. Sixteen $(0.0004 \%)$ patients required reoperations in hospital and $19(0.0004 \%)$ patients required transfer to hospital on the day of surgery. There were only two mortalities within 30 days of surgery reported in the past five years. With regard to patient safety practices, $93 \%$ used antimicrobial prophylaxis, $100 \%$ used strategies to maintain normothermia and $82 \%$ used measures for venous thromboembolism prevention.

CONCLUSION: The present study is the first to report on the Canadian experience in ambulatory surgery facilities and provides insight into current practices at these facilities. Appropriate accreditation of ambulatory surgery facilities, well-established patient safety-related standards of care, careful patient selection and procedures performed by qualified health care professionals with appropriate certification practicing within the scope of their practice form the basis for safe and effective ambulatory surgery.

Key Words: Ambulatory Surgery; Canadian; Outpatient Surgery; Patient Safety; Survey

In recent years, there has been increased interest, from both the $I_{\text {public and the professional medical community, regarding patient }}$ safety and standards of care in Canadian ambulatory surgery facilities where procedures are performed. These health care facilities have been referred to as 'ambulatory surgery' or 'office-based surgery' facilities. Several of the provincial Colleges of Physicians and Surgeons have applied the terms 'nonhospital surgical facilities' (Alberta), 'nonhospital medical and surgical facilities' (British Columbia) and 'out-of-hospital premises' (Ontario) to describe these facilities. The Canadian Association for Accreditation of Ambulatory Surgical Facilities (CAAASF) is a national organization formed in 1990 by physicians to establish and maintain standards to ensure that surgical procedures conducted outside a public hospital are performed safely. The CAAASF has established accreditation standards for staff, in-house

\section{L'évaluation de la sécurité des patients dans les installations de chirurgie ambulatoire : une enquête nationale}

HISTORIQUE : On remarque un intérêt croissant envers la sécurité des patients et les normes de soins dans les installations canadiennes de chirurgie ambulatoire où des opérations chirurgicales sont effectuées. L'Association canadienne d'accréditation des installations de chirurgie ambulatoire (ACAICA) est un organisme national formé pour créer et maintenir des normes afin que les interventions chirurgicales menées à l'extérieur des hôpitaux publics soient effectuées en toute sécurité.

OBJECTIF : Déterminer le nombre d'interventions effectuées chaque année dans les installations membres de l'ACAICA et examiner les taux de complication et plusieurs pratiques essentielles en matière de sécurité des patients.

MÉTHODOLOGIE : Les 69 centres accrédités par l'ACAICA ont été sondés. Ce sondage portait sur les données liées aux interventions, les taux de complication et les interventions en matière de sécurité des patients.

RÉSULTATS : En 2010, on estime que 40240 interventions ont été effectuées. Au total, 263 complications $(0,007 \%)$ ont été déclarées. Seize patients $(0,0004 \%)$ ont dû être réopérés à l'hôpital, tandis que 19 (0,0004 \%) ont dû être transférés à l'hôpital le jour de l'opération. Depuis cinq ans, seulement deux décès ont été déclarés dans les 30 jours suivant l'intervention. Pour ce qui est des pratiques en matière de sécurité des patients, $93 \%$ ont utilisé une prophylaxie antimicrobienne, $100 \%$, des stratégies de maintien de la normothermie et $82 \%$, des mesures de prévention de la thromboembolie veineuse.

CONCLUSION : La présente étude est la première à rendre compte de l'expérience canadienne dans les installations de chirurgie ambulatoire et à donner un aperçu des pratiques qui y sont utilisées. L'accréditation convenable des installations de chirurgie ambulatoire, des normes de soins bien établies en matière de sécurité des patients, une sélection attentive des patients et des interventions effectuées par des professionnels de la santé qualifiés possédant une certification pertinente et travaillant dans leur champ d'activité forment le fondement d'interventions chirurgicales ambulatoires à la fois sécuritaires et efficaces.

quality assurance, medical records, peer-review and quality control, health standards and facility requirements (1).

While several studies from the United States (2-7) have examined patient safety at accredited ambulatory surgery facilities, no study has been conducted to examine the Canadian experience. The aim of the present study was to obtain demographic and procedural information for ambulatory surgery facilities accredited by the CAAASF to gain insight into patient safety and standards of care in Canadian ambulatory surgery facilities.

\section{METHODS}

As of January 2011, the CAAASF had a total of 69 accredited member facilities. Survey questions were developed to gather demographic information about member facilities including location, type of

${ }^{1}$ The Plastic Surgery Clinic, Mississauga; ${ }^{2}$ Division of Plastic and Reconstructive Surgery, University of Toronto; ${ }^{3}$ Cosmetic Surgery Institute,

Toronto; ${ }^{4}$ Division of Plastic Surgery, McMaster University, Hamilton, Ontario; ${ }^{5}$ Division of Plastic and Reconstructive Surgery, Dalhousie

University, St John, New Brunswick

Correspondence: Dr Frank Lista, Canadian Association for Accreditation of Ambulatory Surgical Facilities, 2334 Heska Road, Pickering,

Ontario L1V 2P9. Telephone 905-831-5804,fax 905-831-7248, e-mail csacps@sympatico.ca 
TABLE 1

Types of Canadian Association for Accreditation of Ambulatory Surgical Facilities member sites

Type I: Local anesthesia

Type II: Local anesthesia and sedation

Type III: Local anesthesia, sedation, regional anesthesia, general anesthesia

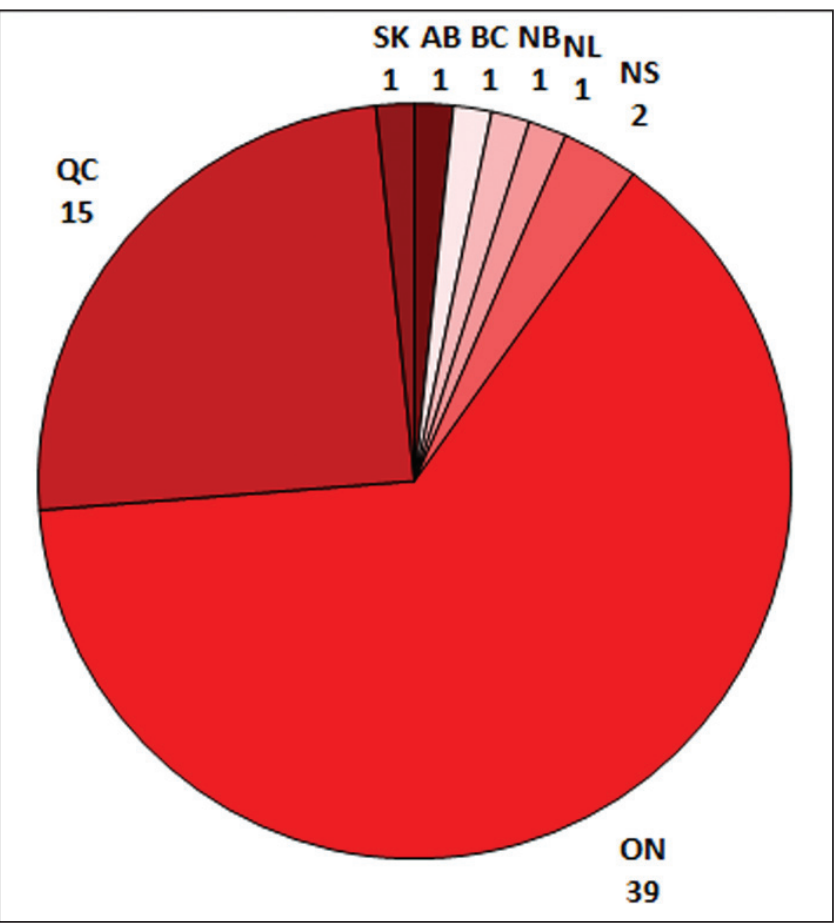

Figure 1) Distribution of respondant Canadian Association for Accreditation of Ambulatory Surgical Facilities member sites according to province. AB Alberta; BC British Columbia; NB New Brunswick; NL Newfoundland and Labrador; NS Nova Scotia; ON Ontario; QC Quebec; SK Saskatchewan

accreditation (Table 1) and the expertise of providers performing procedures in the facilities. The survey sought to obtain information regarding the types and number of procedures performed in the facilities. More importantly, it sought to obtain information regarding the number and type of complications, transfer and admission to hospitals and mortality following a procedure performed at member facilities. The survey focused on the volume of procedures performed per year at each facility, the rate of major complications, and patient safety interventions that were used. The survey questions were developed by consensus by the authors. The survey consisted of 26 questions multiple choice and open-ended - and were used in an attempt to obtain consistent data but to also allow respondents to provide information that they believed was relevant. Respondents were instructed to complete the survey based on their experience in 2010. Surveys were addressed to the medical director of the facility and distributed to each of the member facilities via e-mail, fax and regular mail. In total, there were three separate mailings: February, May and September 2011. Participation was voluntary and respondents had the option of returning surveys anonymously. Completed surveys were returned to CAAASF administrative staff for collating and were subsequently forwarded to the authors.

\section{RESULTS}

Of all CAAASF member facilities surveyed, the response rate was 89\% (61 of 69). Member facilities in Ontario and Quebec accounted for the majority of completed surveys (54 of 61) (Figure 1). The

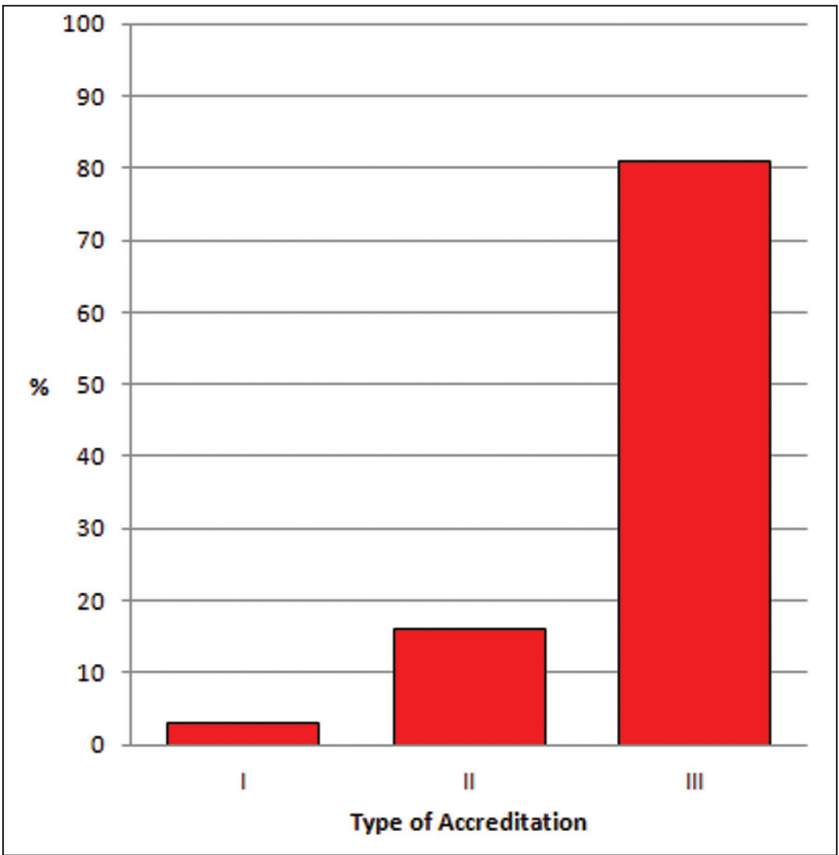

Figure 2) Percentage of respondent Canadian Association for Accreditation of Ambulatory Surgical Facilities members according to accreditation type (see Table 1)

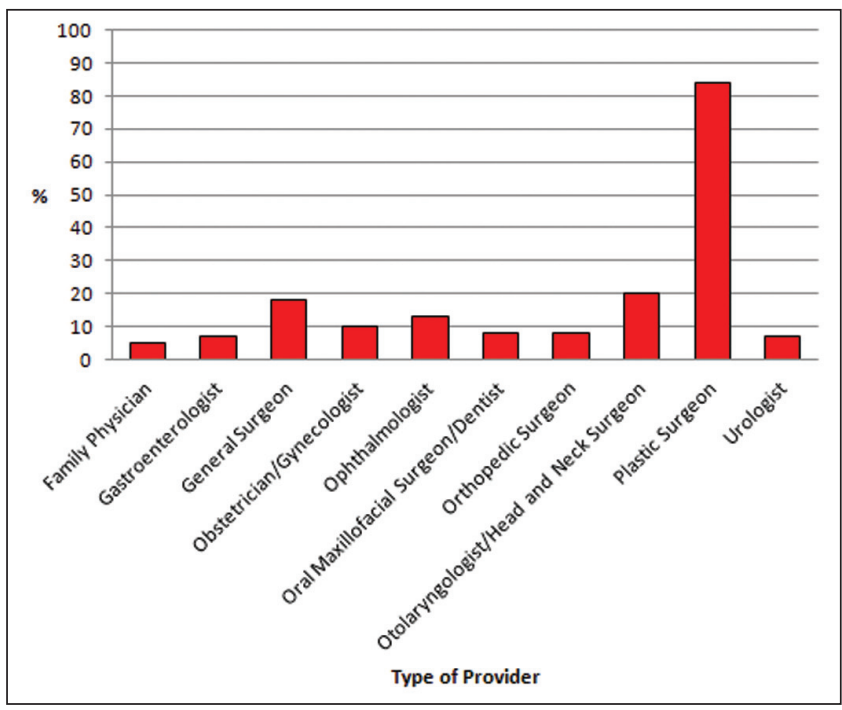

Figure 3) Frequency of type of provider performing procedures at Canadian Association for Accreditation of Ambulatory Surgical Facilities member sites

majority of responses were received from member facilities that had type III accreditation (49 of 61) followed by type II accreditation (10 of 61) (Figure 2).

There was a wide variety of physicians and oral maxillofacial/ dental surgeons who performed procedures at member facilities (Figure 3). Plastic surgeons, ophthalmologists, otolaryngologist/head and neck surgeons, and general surgeons were most frequently cited as performing procedures in CAAASF-accredited facilities. Respondents most commonly reported that cosmetic surgery and plastic surgery procedures were performed at their facilities, followed by hand surgery and bariatric surgery (Figure 4).

In total, 40,240 estimated procedures were performed. A total of 263 complications were reported, yielding in a complication rate of $0.007 \%$ (Table 2). The most commonly reported complications were hematoma, surgical site infections and seroma. 
TABLE 2

Complications reported by Canadian Association for Accreditation of Ambulatory Surgical Facilities member sites

Surgical site infections

Nonsurgical site infections (eg, urinary tract infection, pneumonia, intravenous site, etc)

\section{Hematoma}

Seroma

Deep vein thrombosis

Pulmonary embolism

Cardiac arrhythmia

Severe allergic/anaphylactic reaction

Wound dehiscence/delayed wound healing

Poorly controlled pain

Brochospasm

Pulmonary edema

Vasaovagal response

Rash

Aspiration

Orbital hemorrhage

Colonic perforation

Breast implant deflation

Neuropathy

Fat necrosis

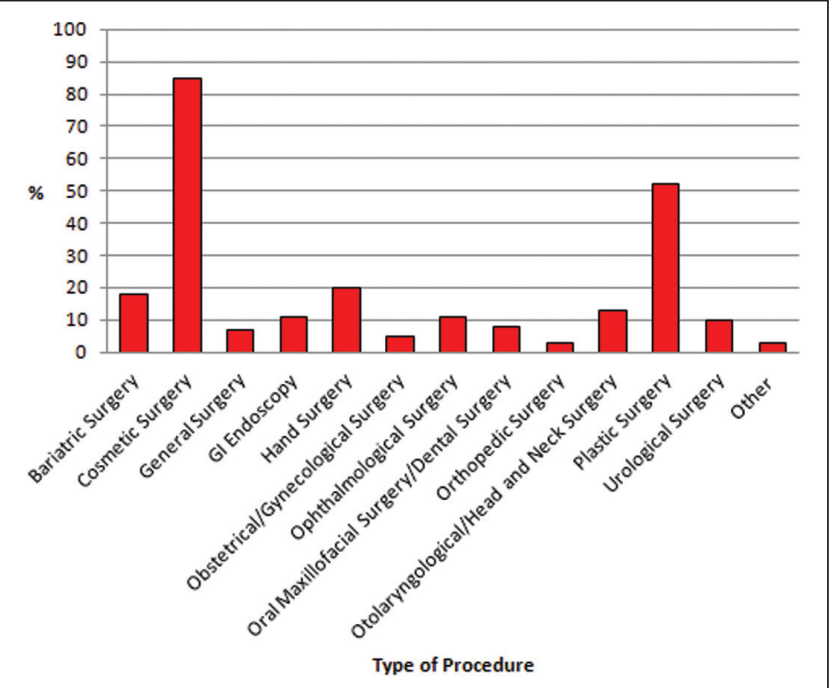

Figure 4) Frequency of type of procedures performed at Canadian Association for Accreditation of Ambulatory Surgical Facilities member sites. GI Gastrointestinal

There were $16(0.0004 \%)$ patients who required reoperations in hospital and $19(0.0004 \%)$ patients who required transfer to hospital on the day of surgery. Between 2006 and 2010, only two mortalities within 30 days of surgery were reported; the causes of death were not reported.

With regard to patient safety interventions, $93 \%$ used antimicrobial prophylaxis (Figure 5). Antimicrobial prophylaxis was most commonly administered within $1 \mathrm{~h}$ before the incision. All (100\%) facilities used various strategies to maintain normothermia. The most commonly used strategies included room temperature control, insulating blankets, forced-air warming blankets and warmed fluids (eg, intravenous, irrigation, implant fill). Eighty-two percent of facilities used measures for venous thromboembolism prevention. Elastic stockings, sequential (pneumatic) compressive devices (eg, leg wrap), and chemoprophylaxis (eg, heparin, low molecular weight heparin, warfarin) were the most commonly cited strategies to decrease the risk of venous thromboembolism.

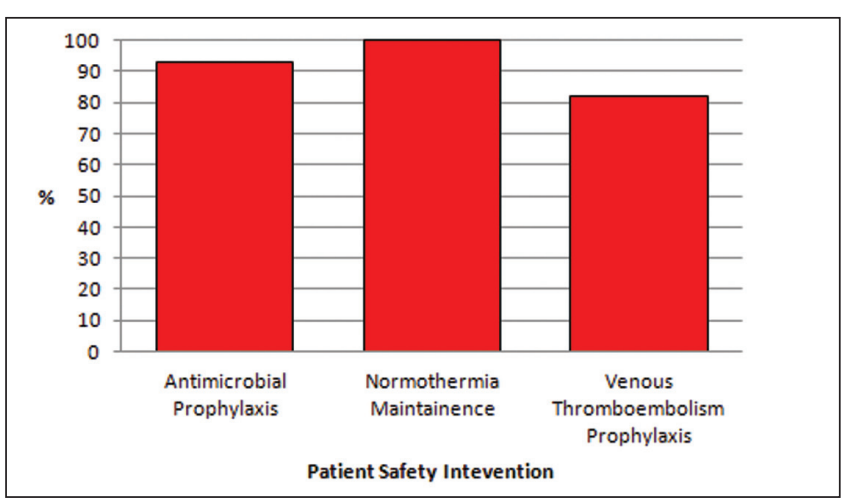

Figure 5) Percentage of Canadian Association for Accreditation of Ambulatory Surgical Facilities member sites that routinely perform benchmark patient safety practices

Forty-four percent of facilities permitted procedures to be performed on patients with obstructive sleep apnea and all facilities had established criteria for preoperative evaluation of these patients. Specifically, respondents were asked to describe what criteria they use to determine whether a patient with obstructive sleep apnea is suitable for surgery in their facility. The responses included requiring the patient to bring their own continuous positive airway pressure machine, preoperative anesthesia/internal medicine consult, preoperative sleep study and/or minimizing narcotic use.

\section{DISCUSSION}

The present study was the first to report on the Canadian experience in ambulatory surgery facilities and provides insight into current practices at these facilities. A diverse group of physicians, in addition to oral maxillofacial/dental surgeons, perform a wide variety of ambulatory surgery procedures at CAAASF-accredited facilities. Of the more than 40,000 procedures performed in 2010, key complication rates (ie, reoperations in hospital, transfer to hospital on the day of surgery, admission to hospital on the day of surgery and mortality within 30 days of surgery) were exceedingly low. This attests to the importance of having procedures performed by appropriately qualified physicians and other health care professionals in accredited health care facilities (8-14). These findings are similar to studies examining patient safety in ambulatory surgery facilities in the United States (2-7). Another positive finding from the present survey related to patient safety practices that were chosen as benchmarks to be studied. There is significant clinical evidence to support the routine practice of appropriate antibiotic prophylaxis to prevent surgical site infections (15), normothermia maintenance to avoid hypothermia (16) and venous thromboembolism prophylaxis $(17,18)$; strategies to address each of these patient safety measures were applied by the majority of member facilities to attempt to decrease the risk of each of these complications.

Although it was reassuring that the vast majority of member facilities performed the patient safety practices that were chosen as benchmarks in the present survey, there appeared to be some variation in the types of interventions that were chosen. While this may be due to different practice patterns and procedures that are performed in each facility, it may represent an opportunity for continuing professional education and development. Another useful function of the CAAASF identified through the present study would be to disseminate patient safety guidelines to help keep health care providers practicing in accredited facilities up to date on current evidence and best practice.

As medical knowledge and technology continue to evolve, it has become possible to perform certain surgeries that had been reserved for hospital and inpatient stays safely in ambulatory surgery facilities on an outpatient basis. Performing procedures in ambulatory surgery or office-based surgery facilities has certain inherent advantages including developing practice models to improve the efficiency of health care delivery, improving the economics of health care delivery, and 
increased convenience for both patients and health care providers (19). Additionally, the shift of these procedures from the hospital to appropriate out-of-hospital premises enables more appropriate hospital resource utilization in the Canadian health care system.

\section{Limitations}

Although there was an exceptionally high response rate to the present survey, the number of procedures performed and key complication rates were an approximation. While the majority of CAAASF member facilities reported exact numbers, some reported estimates. This is likely due to the labour-intensive nature of performing a clinical audit of this type. In the future, it would be useful to specify what type of procedural data should be tracked prospectively to enable more accurate data collection.

In addition, one of the primary goals of the present survey was to study major complications (ie, complications that resulted in transfer or admission to hospital, or reoperation). Routine tracking and review of adverse events is an important aspect of peer review and quality control, and a mandatory criteria for CAAASF accreditation (1). It appears that respondents were transparent with reporting complications because many facilities reported when major complications occurred. However, despite tracking and review of adverse events being a mandatory CAAASF requirement, both the present survey and the information reported herein was completed on a voluntary basis by the CAAASF medical director of each facility and is subject to the inherent biases of self-reporting including under-reporting and false reporting. Additionally, adverse events, including admission to hospital and/or reoperation following discharge from the ambulatory surgery facility, may not be data that are captured in the current framework of our Canadian health care system if a patient is lost to followup - this is true not only for Canadian ambulatory surgery facilities but also for most Canadian hospitals. In recent years, several provinces (eg, Alberta, British Columbia and Ontario) have instituted legislation to ensure mandatory reporting of specific adverse events at ambulatory surgery facilities to the respective provincial medical regulatory bodies (20-22). This legislation will help to ensure accurate reporting of these events and may present an opportunity to study outcomes and potential areas for improvement in patient care. At this time, these data have not been made readily accessible to the public; therefore, the present study remains the singular report on outcomes at Canadian

\section{REFERENCES}

1. The Canadian Association for Accreditation of Ambulatory Surgical Facilities: Criteria for accreditation of ambulatory surgical facilities. < http://caaasf.org/downloads/Criteria.pdf> (Accessed May 15, 2013).

2. Morello DC, Colon GA, Fredricks S, Iverson RE, Singer R. Patient safety in accredited office surgical facilities. Plast Reconstr Surg 1997;99:1496-500.

3. Bitar G, Mullis W, Jacobs W, et al. Safety and efficacy of officebased surgery with monitored anesthesia care/sedation in 4778 consecutive plastic surgery procedures. Plast Reconstr Surg 2003;111:150-6.

4. Byrd HS, Barton FE, Orenstein HH, et al. Safety and efficacy in an accredited outpatient plastic surgery facility: A review of 5316 consecutive cases. Plast Reconstr Surg 2003;112:636-41.

5. Hoefflin SM, Bornstein JB, Gordon M. General anesthesia in an office-based plastic surgical facility: A report on more than 23,000 consecutive office-based procedures under general anesthesia with no significant anesthetic complications. Plast Reconstr Surg 2001;107:243-51.

6. Keyes GR, Singer R, Iverson RE, et al. Analysis of outpatient surgery center safety using an internet-based quality improvement and peer review program. Plast Reconstr Surg 2004;113:1760-70.

7. Keyes GR, Singer R, Iverson RE, et al. Mortality in outpatient surgery. Plast Reconstr Surg 2008;122:245-50.

8. Horton JB, Janis JE, Rohrich RJ. MOC-PS(SM) CME article: Patient safety in the office-based setting. Plast Reconstr Surg 2008;122(3 Suppl):1-21. ambulatory surgery facilities. Finally, it would be useful to specify exactly what types of complications should be tracked in the complication $\log$ that is a requirement for CAAASF membership. Accurate and transparent reporting of complications and adverse events allows for root cause analysis, presenting an opportunity for future prevention and improved standards of care (23).

It is important to note that the results of the present survey may not be reflective of all Canadian ambulatory surgery facilities and are only representative of CAAASF member facilities. Application for CAAASF membership is voluntary and the aim of this organization is to promote high-quality and safe patient care in Canadian ambulatory surgery facilities. However, ambulatory surgery facilities seeking to obtain or maintain CAAASF accreditation must still meet the organization's rigorous standards for staff, in-house quality assurance, medical records, peer-review and quality control, health standards and facility requirements.

\section{CONCLUSION}

The present study is the first to report the Canadian experience in ambulatory surgery facilities and provides insight into current practices at these facilities. More than 40,000 procedures are performed in CAAASF-accredited facilities per year, with very low complication rates. Appropriate accreditation of ambulatory surgery facilities, wellestablished patient safety related standards of care, careful patient selection, and procedures performed by qualified health care professionals with appropriate certification practicing within the scope of their practice form the basis for safe and effective ambulatory surgery.

ACKNOWLEDGEMENT: The authors thank Ms Pat Hewitt for her invaluable help in distribution and collation of surveys.

DISCLOSURES: Dr Lista is the Chairman of the CAAASF and a medical director of CAAASF member facility. Dr Carman is Secretary and Treasurer of the CAAASF and a medical director of CAAASF member facility. Drs Thoma and Lalonde are medical directors of CAAASF member facilities. Drs Ho and Ahmad do not have any relevant disclosures. Presented at the 67th Annual Meeting of the Canadian Society of Plastic Surgeons, June 1, 2013, Calgary, Alberta, and the 40th Annual Meeting of the Canadian Society for Aesthetic Plastic Surgery, September 21, 2013, Vancouver, British Columbia.

9. Rohrich RJ, Parker TH III, Broughton G II, Garza R, Leblanc D. The importance of advanced cardiac life support certification in office-based surgery. Plast Reconstr Surg 2008;121:93e-101e.

10. Horton JB, Reece EM, Broughton G II, Janis JE, Thornton JF, Rohrich RJ. Patient safety in the office-based setting. Plast Reconstr Surg 2006;117:61e-80e.

11. Trussler AP, Tabbal GN. Patient safety in plastic surgery. Plast Reconstr Surg 2012;130:470e-8e.

12. Iverson RE; ASPS Task Force on Patient Safety in Office-Based Surgery Facilities. Patient safety in office-based surgery facilities: I. Procedures in the office-based surgery setting.

Plast Reconstr Surg 2002;110:1337-42.

13. Iverson RE, Lynch DJ; ASPS Task Force on Patient Safety in OfficeBased Surgery Facilities. Patient safety in office-based surgery facilities: II. Patient selection. Plast Reconstr Surg 2002;110:1785-90.

14. Haeck PC, Swanson JA, Iverson RE, et al; ASPS Patient Safety Committee. Evidence-based patient safety advisory:

Patient selection and procedures in ambulatory surgery. Plast Reconstr Surg 2009;124(4 Suppl):6S-27S.

15. Anderson DJ. Surgical site infections. Infect Dis Clin North Am 2011;25:135-53.

16. Lista F, Doherty CD, Backstein RM, Ahmad J. The impact of perioperative warming in an outpatient aesthetic surgery setting. Aesthet Surg J 2012;32:613-20.

17. Murphy RX Jr, Alderman A, Gutowski K, et al. Evidence-based practices for thromboembolism prevention: Summary of the ASPS 
Venous Thromboembolism Task Force Report. Plast Reconstr Surg 2012;130:168e-175e.

18. Somogyi RB, Ahmad J, Shih JG, Lista F. Venous thromboembolism in abdominoplasty: A comprehensive approach to lower procedural risk. Aesthet Surg J 2012;32:322-9.

19. Spring MA, Stoker DA, Holloway J, Weintraub M, Stevens WG. Office-based plastic surgery with general anesthesia: Efficiency of cost and time. Semin Plast Surg 2007;21:99-101.

20. College of Physicians and Surgeons of British Columbia.

Non-Hospital Medical and Surgical Facilities Program. <www.cpsbc. $\mathrm{ca} /$ programs/nhmsfp/standards $>$ (Accessed January 20, 2014).
21. College of Physicians \& Surgeons of Alberta. Non-Hospital Surgical Facility: Standards \& Guidelines. <www.cpsa.ab.ca/libraries/pro_ qofc_non_hospital/NHSF_Standards.pdf?sfvrsn=8>

(Accessed January 20, 2014).

22. College of Physicians and Surgeons of Ontario. Out-of-Hospital Premises Inspection Program. <http://cpso.on.ca/cpso-members/outof-hospital-premises-inspection-program $>$ (Accessed January 20, 2014).

23. Poore SO, Sillah NM, Mahajan AY, Gutowski KA. Patient safety in the operating room: I. Preoperative. Plast Reconstr Surg 2012;130:1038-47. 